\title{
Bone mineral density in subjects with mild asthma randomised to treatment with inhaled corticosteroids or non-corticosteroid treatment for
} two years

\author{
A E Tattersfield, G I Town, O Johnell, C Picado, M Aubier, P Braillon, R Karlström
}

City Hospital, Nottingham, UK A E Tattersfield

Christchurch School of Medicine, Christchurch, New

Zealand

G I Town

University Hospital, Malmö, Sweden O Johnell

Hospital Clinico y Provincial, Barcelona, Spain

C Picado

Hôpital Bichat, Paris, France

M Aubier

Hôpital E Herriot, Lyon, France

P Braillon

AstraZeneca R\&D, Lund, Sweden

R Karlström

Correspondence to: Professor A E Tattersfield, Division of Respiratory Medicine, City Hospital, Nottingham NG5 1PB, UK anne.tattersfield@ nottingham.ac.uk

Received 18 April 2000 Returned to authors 25 August 2000 Revised version received 8 January 2001 Accepted for publication 15 January 2001

\begin{abstract}
Background-Inhaled corticosteroids are clearly beneficial for patients with asthma of moderate severity, but the risks and benefits of using them in patients with milder asthma are less clear. We have compared the change in bone mineral density over 2 years in adults with mild asthma randomised to receive an inhaled corticosteroid or non-corticosteroid treatment.

Methods-Subjects with mild asthma (mean forced expiratory volume in one second $\left(\mathrm{FEV}_{1}\right) \mathbf{8 6 \%}$ predicted, mean age 35 years, taking $\beta$ agonists only) were randomised to receive inhaled budesonide, inhaled beclomethasone dipropionate, or non-corticosteroid treatment for 2 years in a prospective randomised open study in 19 centres in France, New Zealand, Spain, and the UK. The corticosteroid dose was adjusted according to a written selfmanagement plan. The main outcome measure-change in bone mineral density after 6, 12, and 24 months-was measured "blind". Secondary outcomes included lung function, the relation between change in bone density and inhaled steroid dose and change in biochemical markers of bone metabolism.
\end{abstract}

Results-Of 374 subjects randomised, 239 (64\%) completed the study and were included in the analysis. The median daily doses of inhaled budesonide $(n=87)$ and beclomethasone $(n=74)$ were $389 \mu \mathrm{g}$ and $499 \mu \mathrm{g}$, respectively. Subjects treated with an inhaled corticosteroid had better asthma control than those in the reference group $(n=78)$. Change in bone mineral density did not differ between the three groups over the 2 years, nor did it correlate with changes in markers of bone metabolism. The mean change in bone mineral density over 2 years in the budesonide, beclomethasone dipropionate, and reference groups was $0.1 \%$, $-0.4 \%$, and $0.4 \%$ for the lumbar spine and $-0.9 \%,-0.9 \%$, and $-0.4 \%$ for neck of the femur. Mean daily dose of inhaled steroid was related to reduction in bone mineral density at the lumbar spine but not at the femoral neck.

Conclusion-In subjects with mild asthma an inhaled corticosteroid provided better asthma control than alternative noncorticosteroid treatment with no differ- ence in change in bone mineral density over 2 years. The relation between dose of inhaled corticosteroid and change in bone density at the lumbar spine may be due to a direct effect of inhaled corticosteroids on bone. Since inhaled steroid dose is also related inversely to lung function, an effect of asthma severity on bone density was also possible.

(Thorax 2001;56:272-278)

Keywords: bone mineral density; inhaled corticosteroids; asthma

Inhaled corticosteroids are clearly beneficial in subjects with moderate or severe asthma since they are well tolerated, reduce symptoms, and improve quality of life. ${ }^{1-3}$ They are absorbed to some extent, however, and although systemic effects are considerably less than with oral corticosteroids, potential long term adverse effects have to be considered when balancing the risks and benefits for subjects with mild asthma. Recent consensus guidelines on asthma management have been informed predominantly by evidence of efficacy. ${ }^{4}$ The longer term risk-benefit ratio needs to be considered, however, since corticosteroids are often taken for several decades. ${ }^{5}$ The development of osteoporosis is a major concern with oral corticosteroids. ${ }^{6}$ The extent to which inhaled corticosteroids affect bone metabolism and bone density is less clear since the few prospective studies in asthmatic patients have been small $^{5-13}$ and most cross sectional studies have not controlled adequately for prior use of oral corticosteroids. ${ }^{5}$ We therefore looked at change in bone mineral density over 2 years in subjects with mild asthma randomised to receive an inhaled corticosteroid or alternative noncorticosteroid treatment. The relation between change in bone mineral density and mean cumulative dose of inhaled corticosteroid and change in biochemical markers of bone metabolism were secondary objectives.

The study was designed as a pragmatic approach to compare the effects of inhaled corticosteroids and non-corticosteroid treatment, with corticosteroid dose being adjusted according to asthma severity and response to treatment. We were unable to do this in a double blind manner without departing from normal clinical practice or compromising subject safety. The study was therefore randomised but open, although bone mineral density-the 
Table 1 Demographic and mean baseline data for all subjects and subjects completing the study

\begin{tabular}{|c|c|c|c|c|}
\hline \multirow[b]{2}{*}{ Variable } & \multirow[b]{2}{*}{ All subjects } & \multicolumn{3}{|c|}{ Completed subjects } \\
\hline & & $B U D$ & $B D P$ & Reference \\
\hline No (\% female) & $374(55)$ & $87(56)$ & $74(56)$ & $78(49)$ \\
\hline Mean (SD) age (years) & $35(11)$ & $37(11)$ & $36(12)$ & $36(10)$ \\
\hline Weight $(\mathrm{kg})$ & 70 & 70 & 73 & 71 \\
\hline Duration of asthma (years) & 13 & 13 & 13 & 13 \\
\hline Smoking (\% current) & 20 & 19 & 17 & 22 \\
\hline Morning PEF (1/min) & 407 & 403 & 411 & 411 \\
\hline $\mathrm{FEV}_{1}(\%$ pred $)$ & 86 & 86 & 85 & 84 \\
\hline Bronchodilator reversibility (\%) & 10 & 10 & 10 & 11 \\
\hline$\beta_{2}$ agonist use (puffs $/ 24 \mathrm{~h}$ ) & 2.9 & 3.2 & 2.9 & 2.7 \\
\hline \multicolumn{5}{|l|}{ Mean (SD) BMD (g/cm²) } \\
\hline Lumbar spine & $1.15(0.16)$ & $1.15(0.16)$ & $1.13(0.16)$ & $1.19(0.17)$ \\
\hline Hip & $0.98(0.16)$ & $0.96(0.15)$ & $0.97(0.17)$ & $1.0(0.15)$ \\
\hline Total body & $1.17(0.1)$ & $1.17(0.1)$ & $1.19(0.1)$ & $1.19(0.09)$ \\
\hline Vertebral deformity (\%) & 8 & 7 & 7 & 9 \\
\hline \multicolumn{5}{|l|}{ Biochemical markers geometric mean (range): } \\
\hline Osteocalcin $(\mu \mathrm{g} / \mathrm{l})$ & $2.6(0.5-21.3)$ & $2.3(0.5-21.3)$ & $2.8(0.5-18.4)$ & $2.3(0.5-12.5)$ \\
\hline Deoxypyridinoline ( $\mathrm{mol} / \mathrm{mol}$ creatinine) & $12.9(3.3-78)$ & $12.5(6.4-36)$ & $12.5(3.3-40)$ & $12.8(3.6-47)$ \\
\hline $\begin{array}{l}\text { Pyridinoline crosslinks }(\mu \mathrm{mol} / \mathrm{mol} \\
\text { creatinine) }\end{array}$ & $48.1(12.6-144)$ & $48.0(21-125)$ & $45.7(15.6-111)$ & $46.0(19-136)$ \\
\hline
\end{tabular}

$\mathrm{BUD}=$ budesonide; $\mathrm{BDP}=$ beclomethasone dipropionate; $\mathrm{PEF}=$ peak expiratory flow; $\mathrm{FEV}_{1}=$ forced expiratory flow in one second; $\mathrm{BMD}=$ bone mineral density.

main end point - was measured by radiographers unaware of the treatment the subject was receiving.

\section{Methods}

The study was carried out in 19 centres in France, New Zealand, Spain, and the UK. The protocol was approved by the local ethics committee for each centre and subjects gave written informed consent.

SUBJECTS

Subjects had to be aged 20-60 years, have relatively mild asthma, and a pre-bronchodilator $\mathrm{FEV}_{1}$ of $65 \%$ predicted $^{14}$ or above. They had to be taking a $\beta_{2}$ agonist only and no corticosteroid treatment by any route during the previous 3 months (apart from 1\% hydrocortisone cream) and no more than 1 month of treatment with oral corticosteroids in the previous year or inhaled or nasal corticosteroids in the previous 6 months. Subjects had to have taken at least four puffs of a short acting $\beta_{2}$ agonist and show less than $25 \%$ variability in morning peak expiratory flow (PEF, expressed as a percentage of the highest value) during the last 7 days of the run in period with complete data. Subjects were excluded if they had other medical conditions, had taken drugs known to affect bone mineral density, had required more than 2 weeks of bed rest in the previous 6 months, or were pregnant, lactating or at risk of becoming pregnant.

\section{MEASUREMENTS}

$\mathrm{FEV}_{1}$ was measured by spirometry as the best of three measurements. Bronchodilator reversibility was assessed as change in $\mathrm{FEV}_{1} 15 \mathrm{~min}$ after inhalation of $1 \mathrm{mg}$ terbutaline sulphate by Turbohaler. PEF was measured at home (Vitalograph peak flow meter, Vitalograph, Buckingham, UK) as the best of three attempts with morning PEF being measured before any bronchodilator.

Bone mineral density $\left(\mathrm{g} / \mathrm{cm}^{2}\right)$ was measured at the second to fourth lumbar vertebrae (posterior/anterior view, excluding fractured vertebrae), at the neck of the non-dominant femur, and for total body with the subject supine using dual energy $x$ ray absorptiometry (Hologic QDR; Hologic Inc, Waltham, MA, USA or Lunar-DPX-L scanner; Lunar Corporation, Madison, Wisconsin, USA). Calibration was carried out daily using a phantom and across centres at the beginning and end of the study using the same European Spine Phantom. ${ }^{15}$ All calibration checks were assessed by an independent company (Bio-Imaging Technologies Inc, West Trenton, NJ, USA). Vertebral fractures were identified by morphometry of the lateral thoracic and lumbar spine and defined as a reduction in anterior, medial, or posterior height by at least $20 \%$ and $4 \mathrm{~mm}$.

Serum and early morning urine were stored at $-20^{\circ} \mathrm{C}$. Serum was analysed for osteocalcin concentrations by fluoroimmunoassay (FEIA Cap System, Pharmacia \& Upjohn, Södertälje, Sweden) and urine for deoxypyridinoline and pyridinoline crosslinks by high performance liquid chromatography. ${ }^{16}$

STUDY PROTOCOL

The study was designed to enable patients to maintain good asthma control. After a 2-4 week run in period in which subjects took their usual treatment, those fulfilling the entry criteria were randomised using a computer generated sequence stratified by sex to one of three treatment arms: inhaled budesonide $200 \mu \mathrm{g}$ twice daily (via Turbohaler), inhaled beclomethasone dipropionate $250 \mu$ twice daily (by metered dose inhaler with a spacing device (Volumatic)), or alternative non-steroid treatment (reference group). Inhaled corticosteroids were to be taken after a bronchodilator, if used, and subjects were asked to rinse their mouth after the inhalation. For subjects in the reference group the study doctors were asked to prescribe any asthma treatment they considered appropriate other than an inhaled corticosteroid - for example, a long acting $\beta_{2}$ agonist, sodium cromoglycate, nedocromil sodium, ipratropium bromide or theophylline. Inhaler technique was checked in all subjects.

Subjects were seen in the clinic every $4( \pm 1)$ weeks for the first 3 months and then every 3 
Table 2 Use of oral and inhaled corticosteroids in subjects who completed and those who failed to complete the study

\begin{tabular}{lrrr}
\hline & BUD & BDP & Reference \\
\hline Subjects who completed: & & & \\
Total = 239 & 87 & 74 & 78 \\
No of patients needing oral steroids & 20 & 14 & 25 \\
No of courses of oral steroids & 33 & 22 & 52 \\
Mean total dose of oral steroids per patient treated (mg) & 293 & 466 & 322 \\
Median daily dose inhaled steroid ( $\mu \mathrm{g})$ & 389 & 499 & - \\
& & & \\
Subjects who failed to complete: & 38 & 46 & 51 \\
Total = 135 & 3 & 7 & 18 \\
No of patients needing oral steroids & 5 & 12 & 44 \\
No of courses of oral steroids & 236 & 244 & 773 \\
Mean total dose of oral steroids per patient treated (mg) & 406 & 500 & - \\
Median daily dose inhaled steroid $(\mu \mathrm{g})$ & & & \\
\hline
\end{tabular}

BUD = budesonide; $\mathrm{BDP}=$ beclomethasone dipropionate.

months ( \pm 2 weeks) at the same time of day. Patients handed in their diary cards at each visit and compliance with treatment and possible adverse effects were assessed. $\mathrm{FEV}_{1}$ and bronchodilator reversibility were assessed at baseline, at 1 month, and then 6 monthly. Subjects were asked not to take a bronchodilator for 6 hours before visits involving spirometric tests and to fast overnight prior to the visits requiring a first morning void urine sample or venous blood (months 1 and 3 and then every 6 months). Bone mineral density was measured at baseline and at 6,12 , and 24 months and a lateral radiograph of the thoracic and lumbar spine was taken at the start and end of the study.

Throughout the study subjects recorded morning and evening PEF, all medication, and daytime and night time asthma symptoms on a 4 -point scale $(0=$ no symptoms to $3=$ subject unable to perform usual activities or sleep normally). Peak flow charts were marked to enable subjects to identify a reduction in morning PEF to below $85 \%$ and $70 \%$ of values during the last seven completed days in the previous diary card (baseline values).

EXACERBATIONS

A mild exacerbation was defined as a fall in morning PEF to below $85 \%$ of the previous baseline and use of more than four puffs of relief bronchodilator a day on two of the preceding 7 days. A severe exacerbation was defined as a fall in morning PEF to below 70\% of baseline.

MANAGEMENT PLAN

The management plan was designed to enable patients to take the lowest dose of treatment necessary to provide effective asthma control. For mild exacerbations, subjects taking an inhaled corticosteroid were instructed to double the daily dose up to a maximum of $1600 \mu \mathrm{g}$ budesonide or $2000 \mu \mathrm{g}$ beclomethasone dipropionate and to stay on the higher dose for 7 days after their peak flow had reached $90 \%$ of previous baseline before returning to the previous dose. If their peak flow did not reach the $90 \%$ value within 7 days or if it fell below $70 \%$ of the previous baseline they were asked to contact the clinic whereupon a short course of oral corticosteroids was to be considered. Subjects in the reference treatment group were asked to contact their study doctor who would decide what further treatment should be given. For severe exacerbations all subjects were asked to contact the study doctor and take a short course of oral corticosteroids according to their usual practice (prednisolone tablets provided).

Longer term adjustments to inhaled corticosteroid doses were made at clinic visits. Subjects were instructed to double their inhaled corticosteroid dose if they had had two or more mild exacerbations since the last visit or if, during the last 7 days, they had had three or more nights with asthma symptoms or used 22 puffs or more of a bronchodilator. They were told to halve their inhaled steroid dose to a minimum of $200 \mu \mathrm{g}$ daily if, over the last 28 days, they had had no exacerbations, symptoms on no more than two nights, and no more than 32 puffs of short acting $\beta_{2}$ agonist.

ADDITIONAL TREATMENT

Subjects in the reference group who required more than three courses of oral corticosteroids were withdrawn from the study at the start of the fourth exacerbation. For subjects in the inhaled corticosteroid group additional treatment could be used such as a long acting $\beta_{2}$ agonist if asthma control was not achieved with $1600 \mu \mathrm{g}$ budesonide or $2000 \mu \mathrm{g}$ beclomethasone. Nasal steroids were only allowed if other nasal medication was ineffective and it was the same corticosteroid as the subject was inhaling. The only dermatological steroid allowed was $1 \%$ hydrocortisone cream.

\section{STUDY POWER}

The primary end point was change in bone mineral density over the 2 years. With 85 subjects in each treatment group the study had $90 \%$ power to detect a difference in change in bone mineral density between any two treatments of $0.5 \mathrm{SD}$ at the $5 \%$ level of significance, assuming a mean within subject SD of $3-4 \%$ over 2 years, which was the best estimate available (O Johnell, personal communication).

ANALYSIS OF DATA

The primary analysis was carried out on the population that completed the study since an adverse effect was the primary end point. An intention-to-treat analysis was also carried out but the results did not differ appreciably and are not presented. Bone mineral density was expressed as a percentage of baseline to allow for any differences between equipment at different sites. Missing values between measured values were replaced by linear interpolation for descriptive purposes. Change in bone mineral density in the three treatment groups was compared using ANOVA with treatment, country, sex, age group, and baseline bone mineral density as factors in the model. Change in bone mineral density over 2 years was related to dose of inhaled corticosteroid, to mean lung function over the 2 years in the reference group and also, with Bonferroni correction for multiple comparison, to change in markers of bone metabolism.

Diary card data were used to obtain mean morning and evening PEF, mean daily dose of 

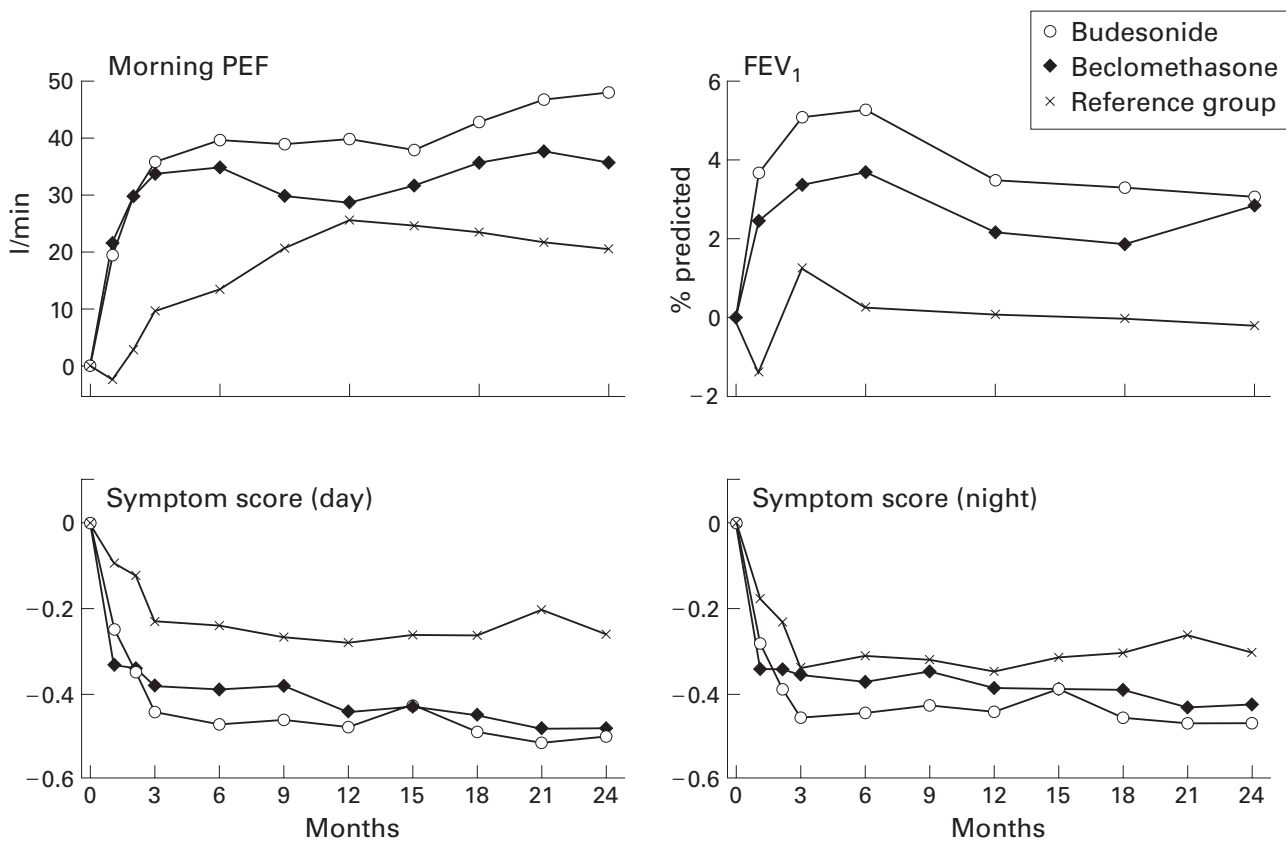

Figure 1 Mean change in peak expiratory flow (PEF) and forced expiratory volume in one second (FEV $)$ and in daytime and night time symptom score (range 0-3) in subjects taking budesonide, beclomethasone, and reference therapy for 2 years.

inhaled corticosteroid, and total dose of prednisolone or prednisone if taken between visits.

\section{Results}

Of the 511 subjects enrolled into the study, 377 were randomised, 374 started treatment, and $239(64 \%)$ completed the 2 year study $(87,74$,

Table 3 Mean (SD) \% change in bone mineral density from baseline in subjects completing the study

\begin{tabular}{|c|c|c|c|c|c|c|}
\hline & \multicolumn{2}{|c|}{$B U D$} & \multicolumn{2}{|c|}{$B D P$} & \multicolumn{2}{|c|}{ Reference } \\
\hline & $n$ & Mean (SD) & $n$ & Mean (SD) & $n$ & Mean (SD) \\
\hline Lumbar spine & 77 & & 68 & & 75 & \\
\hline Month 6 & & $-0.1(2.7)$ & & $-0.1(2.8)$ & & $0.5(2.4)$ \\
\hline Month 12 & & $0.4(3.2)$ & & $-0.1(2.8)$ & & $-0.0(2.6)$ \\
\hline Month 24 & & $0.1(3.3)$ & & $-0.4(3.7)$ & & $0.4(3.5)$ \\
\hline Neck of femur & 79 & & 70 & & 75 & \\
\hline Month 6 & & $-0.2(3.1)$ & & $-0.3(3.6)$ & & $-0.7(3.2)$ \\
\hline Month 12 & & $-0.7(3.3)$ & & $-0.8(4.3)$ & & $-0.3(3.6)$ \\
\hline Month 24 & & $-0.9(3.7)$ & & $-0.9(4.5)$ & & $-0.4(4.1)$ \\
\hline Total body & 70 & & 60 & & 64 & \\
\hline Month 6 & & $-0.1(2.1)$ & & $-0.1(1.6)$ & & $0.4(2.2)$ \\
\hline Month 12 & & $0.3(1.9)$ & & $0.2(1.8)$ & & $0.5(2.3)$ \\
\hline Month 24 & & $0.6(2.2)$ & & $0.4(2.3)$ & & $0.9(2.3)$ \\
\hline
\end{tabular}

$\mathrm{BUD}=$ budesonide; $\mathrm{BDP}=$ beclomethasone dipropionate.

Table 4 Estimated difference (95\% CI) between treatments in \% change in bone mineral density over two years after adjusting for baseline, age (group), sex, and country

\begin{tabular}{lllr}
\hline Site & BUD v Reference & BDP v Reference & \multicolumn{1}{c}{ BUD v BDP } \\
\hline Lumbar spine & $-0.35(-1.46$ to 0.76$)$ & $-0.83(-1.99$ to 0.32$)$ & $0.49(-0.65$ to 1.62$)$ \\
Neck of femur & $-0.70(-2.00$ to 0.60$)$ & $-0.52(-1.87$ to 0.83$)$ & $-0.18(-1.50$ to 1.14$)$ \\
Body & $-0.42(-1.17$ to 0.33$)$ & $-0.55(-1.33$ to 0.23$)$ & $0.13(-0.64$ to 0.90$)$ \\
\hline
\end{tabular}

$\mathrm{BUD}=$ budesonide; $\mathrm{BDP}=$ beclomethasone dipropionate.

Table 5 Geometric mean values (CV\%) for the area under the curve for biochemical markers of bone metabolism over 2 years expressed as \% change from baseline

\begin{tabular}{llll}
\hline & \multicolumn{1}{l}{ BUD } & \multicolumn{1}{l}{ BDP } & Reference \\
\hline Serum osteocalcin & $132(81)$ & $104(71) \dagger$ & $141(101)$ \\
Urinary deoxypyridinoline & $92(34)$ & $105(38)^{\star}$ & $96(29)$ \\
Urinary pyridinoline & $90(30)$ & $101(37)^{\star}$ & $95(27)$ \\
\hline
\end{tabular}

$\mathrm{CV}=$ coefficient of variation.

${ }^{\star} \mathrm{p}<0.05$ compared with budesonide.

$\mathrm{tp}<0.05$ compared with reference treatment. and 78 in the budesonide, beclomethasone, and reference groups, respectively). Of the 135 subjects who failed to complete, $30 \%$ discontinued in the first 3 months. The reasons for stopping in the budesonide $(n=38)$, beclomethasone $(n=46)$, and reference $(n=51)$ groups were worsening asthma $(n=0,1,8$, respectively), adverse effects of treatment $(\mathrm{n}=4,2,5$, respectively), and personal reasons or protocol violations $(n=34,43,38$, respectively).

COMPARISON BETWEEN GROUPS

The three groups had similar demographic characteristics, lung function, and bone mineral density at baseline (table 1) and values for subjects completing the study were similar to those for subjects who failed to complete (data not shown). Reference group subjects were treated with one or more of the following in addition to short acting $\beta_{2}$ agonists: nedocromil or sodium cromoglycate $(n=57)$, long acting $\beta_{2}$ agonist $(n=31)$, and theophylline $(n=11)$.

\section{Steroid dose}

The median daily dose of budesonide and beclomethasone in subjects allocated to inhaled corticosteroids was $389 \mu \mathrm{g}$ (range 1331729) and $499 \mu \mathrm{g}$ (range 176-1906), respectively. Ten subjects taking budesonide and 18 taking beclomethasone took more than $1000 \mu \mathrm{g} /$ day on average and 12 and 13 subjects, respectively, required an additional bronchodilator or cromone. The reference group had more courses of oral corticosteroids than the inhaled steroid groups (table 2) and a higher total dose of prednisolone or prednisone (8050 mg compared with $5860 \mathrm{mg}$ (budesonide group) and $6524 \mathrm{mg}$ (beclomethasone group)). Five subjects had intramuscular or intravenous corticosteroids during the study (one reference, two in each inhaled steroid group). 

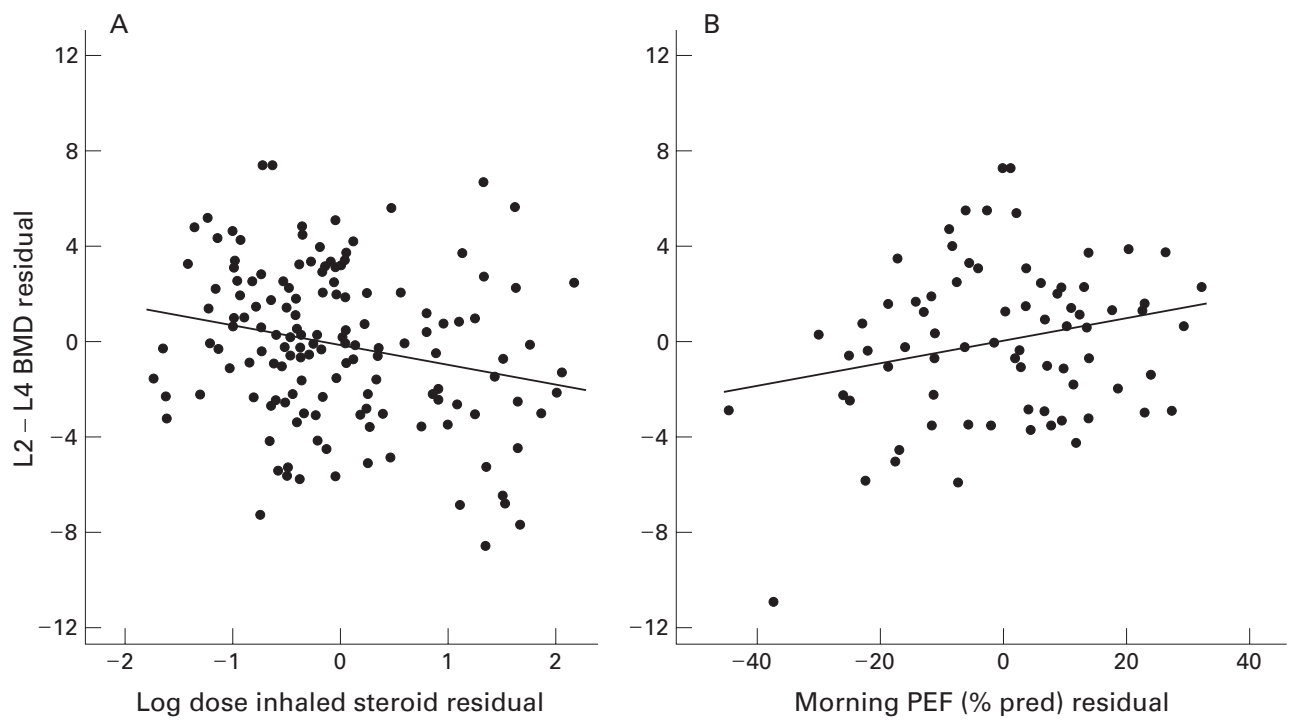

Figure 2 Relation between change in bone mineral density at the lumbar spine and $(A)$ total inhaled steroid dose among patients taking budesonide and beclomethasone and (B) mean morning peak flow over the 2 years in the reference group. Changes in bone mineral density, inhaled steroid dose, and peak flow are expressed as residuals (that is, the residual effect when other factors such as age, centre, etc have been taken into account). Use of residuals enables the relationship between the two variables to be shown after allowing for other factors.

\section{Asthma control}

The reduction in daytime and night time symptoms and in relief bronchodilator use seen during the first 3 months in all three groups was maintained throughout the study (fig 1). The increase in morning PEF was more rapid and more marked in the subjects taking an inhaled corticosteroid (mean increase at 2 years 48,36 , and $201 / \mathrm{min}$ in the budesonide, beclomethasone and reference groups, respectively). The change in $\mathrm{FEV}_{1}$ showed a broadly similar pattern with an early increase in the two groups taking an inhaled corticosteroid. Among these patients, mean $\mathrm{FEV}_{1}$ and morning PEF during the treatment period were inversely related to mean dose of inhaled corticosteroid (both $\mathrm{p}<0.001$ ).

Bone mineral density and vertebral fractures Fifteen patients were excluded from the bone mineral density analysis because of missing or delayed measurements and occasional scans were missing or unsatisfactory. Data were available for $92 \%, 94 \%$, and $81 \%$ of scans for lumbar spine, femoral neck, and total body bone mineral density, respectively. There were no significant differences in the changes in mean bone mineral density between the three groups at any time or at any site (tables 3 and

Table 6 Multivariate regression analysis for within subject changes over 2 years

\begin{tabular}{lll}
\hline & $\begin{array}{c}\text { Regression } \\
\text { coefficient }\end{array}$ & 95\% CI \\
\hline $\begin{array}{l}\text { Change in \% BMD from baseline for each }{ }^{2} \text { log change in mean } \\
\text { dose inhaled corticosteroid }{ }^{\star} \dagger\end{array}$ & \\
L2-L4 & -0.82 & -1.43 to -0.21 \\
L2-L4 further adjusted for initial FEV ${ }_{1}$ & -0.80 & -1.45 to -0.15 \\
Neck of femur & -0.21 & -0.95 to 0.53 \\
Reference group: change in \% BMD at L2-L4 from baseline & & \\
$\quad$ with each change in \% predicted lung function† & 0.05 & -0.001 to 0.10 \\
$\quad$ Mean morning PEF & 0.03 & -0.03 to 0.09 \\
Mean FEV $_{1}$ &
\end{tabular}

*In patients taking inhaled corticosteroids.

† After allowing for treatment, country, sex, age and baseline BMD.

$\mathrm{L} 2-\mathrm{L} 4=2$ nd to 4 th lumbar spine; $\mathrm{BMD}=$ bone mineral density; $\mathrm{PEF}=$ peak expiratory flow

$\mathrm{FEV}_{1}=$ forced expiratory volume in one second; $95 \% \mathrm{CI}=95 \%$ confidence intervals.
4). Only one subject, on budesonide, developed fractures (vertebral) during the study.

\section{Markers of bone metabolism}

Comparison of change in the three markers of bone metabolism over time (as area under the curve) between groups showed no significant differences between budesonide and reference treatment. The beclomethasone group had lower osteocalcin levels than the reference group and higher urinary markers than the budesonide group (table 5).

\section{Adverse effects}

The most frequent adverse effects reported were respiratory, particularly asthma, but with no differences between groups. Compared with the reference group, subjects in the beclomethasone and budesonide groups complained more frequently of upper respiratory tract infections (23\% and $20 \%$ versus $12 \%)$ and back pain ( $8 \%$ and $7 \%$ versus $2 \%)$. Dysphonia ( $1 \%$ and $2 \%$ versus $1 \%$ ) and oral candidiasis $(2 \%$ and $3 \%$ versus $0 \%)$ were reported infrequently.

WITHIN SUBJECT CHANGES IN BONE MINERAL DENSITY

The within subject SD for bone mineral density in the lumbar spine was $3.4 \%$ (table 3 ).

In subjects taking an inhaled corticosteroid the mean dose of inhaled steroid correlated with the fall in bone mineral density over 2 years at the lumbar spine $(p<0.01)$ but not at the femoral neck (fig $2 \mathrm{~A}$, table 6 ). When baseline $\mathrm{FEV}_{1}$ was added to the model there was little change to the regression coefficient $(-0.80$ versus -0.82 ) and the findings remained statistically significant $(p=0.016)$. Fall in bone density also showed a positive correlation with mean morning PEF in the reference group of borderline statistical significance $(\mathrm{p}=0.057)$ but not with $\mathrm{FEV}_{1}$ (fig 2B, table 6). Change in 
bone mineral density did not correlate with change in markers of bone metabolism.

\section{Discussion}

This study was designed to compare the effects of an inhaled corticosteroid or alternative noncorticosteroid treatment on change in bone mineral density over 2 years in subjects with mild asthma who had not previously taken an inhaled corticosteroid. We found no significant difference in the change in bone mineral density at the lumbar spine, femoral neck, or total body over the 2 years between the three groups. Asthma control was better in the subjects receiving an inhaled corticosteroid.

Few clinicians question the value of inhaled corticosteroids for those with asthma of moderate severity, but the balance between risk and benefit is less clear for subjects with mild asthma. Inhaled corticosteroids have systemic activity due to absorption from the lung and, to some extent, from the gastrointestinal tract, ${ }^{2}$ and the extent to which their long term use will contribute to problems such as osteoporosis in the future is uncertain. Any direct effects of inhaled corticosteroids on bone need to be weighed against the fact that, when used sensibly, they should reduce the need for courses of oral corticosteroids, as seen in this study.

The study was designed to reflect current practice as far as possible, so we allowed doctors to prescribe the reference therapy they considered appropriate. Since treatment needed to be adjusted safely and appropriately during the study according to treatment response, a double blind study would have been unwieldy. We therefore opted for a non-blind study but with bone mineral density measurements made single blind. Similarly, because this was a pragmatic study, we did not attempt to measure compliance. Our findings are likely to be influenced by the choice of drugs used by the reference group in addition to short acting $\beta_{2}$ agonists - usually nedocromil or sodium cromoglycate with long acting $\beta_{2}$ agonists and theophylline being used less frequently.

The groups had mild asthma as judged by symptoms and a mean $\mathrm{FEV}_{1}$ of $86 \%$ predicted. Following the introduction of treatment, all three groups showed a reduction in symptoms and $\beta$ agonist use with little difference between the groups. The increase in $\mathrm{FEV}_{1}$ and PEF was more marked and more rapid in those treated with an inhaled corticosteroid. The effects seen in the corticosteroid treated groups were achieved with a mean daily dose of budesonide or beclomethasone of $389 \mu \mathrm{g}$ and $499 \mu \mathrm{g}$, respectively, though a few subjects had considerably higher doses (28 subjects were taking more than $1000 \mu \mathrm{g} /$ day). Subjects in the reference group had twice as many courses of oral steroids as those taking an inhaled corticosteroid.

The lack of significant difference in change in mean bone mineral density is in keeping with several small prospective studies in patients with asthma, ${ }^{7-13} 17$ although one study showed a fall in bone mineral density in nine patients taking beclomethasone dipropionate compared with 15 taking fluticasone propionate. ${ }^{11} \mathrm{~A}$ study of 194 patients with chronic obstructive pulmonary disease showed no change in bone mineral density with budesonide $800 \mu \mathrm{g}$ daily over 3 years. ${ }^{18}$ There are few data on the repeatability of bone mineral density measurements, but our assumption for the power calculations of a within subject SD of 3-4\% for lumbar spine bone mineral density was similar to the $3.4 \%$ seen during the study.

Some caution is needed in interpreting the findings in this study. Bone mineral density is affected by many factors including the menopause, change in weight, and cigarette smoking, although these did not differ between the groups at baseline. Also, $36 \%$ of patients failed to complete the study, a figure which is comparable to that in other multicentre studies that require diary cards to be completed daily-for example, $18 \%$ dropout in one year in the FACET study. ${ }^{19}$ More subjects discontinued the study in the reference group and this may have introduced bias. The study is not able to determine the effect of an inhaled corticosteroid per se since the use of oral steroids is a confounding factor in all groups and more so with the reference group than the inhaled steroid groups. Nevertheless, even the subjects in the reference group averaged less than one course per subject during the study.

Although there was no difference in change in bone mineral density between the three groups, we did find a relationship between the dose of inhaled corticosteroid and a fall in bone mineral density over the 2 years at the lumbar spine but not the femoral neck. Boulet and colleagues found a similar association with higher doses of inhaled corticosteroid in a 3 year prospective study ${ }^{13}$ and a similar relationship was described recently in a large cross sectional study of patients with asthma aged 20-40 years. ${ }^{20}$ The relation between inhaled corticosteroid dose and bone mineral density could be due to a direct effect of corticosteroids on bone or to an indirect effect related to asthma severity since patients taking higher doses of inhaled corticosteroid had lower mean morning PEF and $\mathrm{FEV}_{1}$ values. Patients with more severe asthma might exercise less, for example, though this would perhaps be surprising in this population of patients with mild asthma. The fall in bone density in the reference group, who did not take an inhaled corticosteroid, was associated with lower mean morning PEF values, of borderline statistical significance, but not with $\mathrm{FEV}_{1}$. To try to allow for asthma severity we added baseline $\mathrm{FEV}_{1}$ to the model and this did not modify the relation between inhaled corticosteroid and bone mineral density, which supports the theory that the fall in bone density is due to a direct effect of inhaled corticosteroid rather than asthma. The group comparison may have shown no difference because most patients were taking a low dose of inhaled corticosteroid and because of confounding by oral corticosteroids.

There was no difference in the markers of bone metabolism between the budesonide group and the reference group. Osteocalcin levels were lower and urinary metabolites were 
higher in the beclomethasone group than in the reference and budesonide groups, respectively. The relation between these markers of bone metabolism and change in bone mineral density or fracture risk is not clear, ${ }^{21}$ but our findings are in keeping with beclomethasone having more systemic activity than the treatment taken by the other two groups. This may relate to differences in dose, or inhaler, or because beclomethasone is absorbed to a greater extent than budesonide. ${ }^{51322}$

In conclusion, this study shows that, in patients with mild asthma, treatment with an inhaled corticosteroid provides better asthma control than the alternative treatment chosen by physicians. There was no difference in mean change in bone mineral density between the three groups over 2 years, although the fall in bone mineral density was related to the dose of inhaled corticosteroid. These data suggest that low to moderate doses of inhaled corticosteroids cause little change to bone mineral density over 2 years.

This study was funded by AstraZeneca R\&D, Lund. We thank Jan Ekelund for statistical support and all the investigators who took part in the study. The centres that took part are identified below by the lead clinician: Professor M Aubier, Paris; Dr Charle Lemerre, Nimes; Dr Jean Ordonneau, Nantes; Professor Philippe Godard, Montpellier; Professor Yves Pacheco, Pierre Benite, Professor André Taytard, Pessac; Professor André Bern Tonnel, Lille; Professor Daniel Vervloet, Marseille; Dr Cesar Picado, Barcelona; Dr Julio Rubio, Barcelona; Dra Ana Cisteró, Barcelona; Dr Federico Manresa, Barcelona; Dr Fernando Duce, Zaragoza; Dr José María Marín Trigo, Zaragoza; D Miguel Perpiñá, Valencia; Dr G Ian Town, Christchurch; Dr Robin Taylor, Dunedin; Dr Richard Beasely, Wellington; Professor Anne E Tattersfield, Nottingham; Dr Douglas Robertson, Glasgow.

1 Haahtela T, Jarvinen M, Kava T, et al. Comparison of a beta 2-agonist, terbutaline, with an inhaled corticosteroid, budesonide, in newly detected asthma. $N$ Engl $f \mathrm{Med}$ 1991;325:388-92.

2 Barnes PJ, Pedersen S. Efficacy and safety of inhaled corticosteroids in asthma. Am Rev Respir Dis 1993;148:S126.

3 Juniper EF, Svensson K, O'Byrne PM, et al. Asthma quality of life during one year of treatment with budesonide with or of life during one year of treatment with budesonide
without formoterol. Eur Respir f 1999;14:1038-43.

4 British Thoracic Society. The British guidelines on asthma management: 1995 review and position statement. Thorax 1997;52(Suppl 1):S1-21.
5 Geddes DM. Inhaled corticosteroids: benefits and risks. Thorax 1992;47:404-7.

6 Smith R. Corticosteroids and osteoporosis. Thorax 1990;45: 573-8.

7 Gallacher SJ, Anderson K, Fraser WD, et al. The effect of inhaled corticosteroids on bone density in asthmatic patients. Curr Res Osteo Bone Mineral Meas 1994;147:A293.

8 Herrala JT, Puolijoki H, Impivaara O, et al. Bone mineral density in asthmatic women on high-dose inhaled beclomethasone dipropionate. Am 7 Respir Crit Care Med 1995;151:A374.

9 Hatton MQ, Oldroyd B, Stead R, et al. Bone mineral density changes in women taking inhaled corticosteroids. Thorax 1992;47:228-9.

10 Baraldi E, Bollini MC, De Marchi A, et al. Effect of beclomethasone dipropionate on bone mineral content assessed by -ray densitometry in asthmatic children: a longitudinal evaluation. Eur Respir f 1994;7:710-4.

11 Egan JJ, Maden C, Kalra S, et al. A randomized, double-blind study comparing the effects of beclomethasone and fluticasone on bone density over two years. Eur Respir f 1999;13:1267-75.

12 Hughes JA, Conry BG, Male SM, et al. One year prospective open study of the effect of high dose inhaled steroids, fluticasone propionate, and budesonide on bone markers and bone mineral density. Thorax 1999;54:223-9.

13 Boulet L-P, Milot J, Gagnon L, et al. Long-term influence of inhaled corticosteroids on bone metabolism and density. Am 7 Respir Crit Care Med 1999;159:838-44.

14 Quanjer PH, Tammeling GJ, Cotes JE, et al. Lung volumes Quanjer PH, Tammeling GJ, Cotes JE, et al. Lung volumes
and forced ventilatory flows: Report Working Party Standardization of Lung Function Tests, European Community for Steel and Coal: official statement of the European Respiratory Society. Eur Respir f 1993;6:5-40.

15 Genant HK, Grampp S, Gluer CC, et al. Universal standardization for dual X-ray absorptiometry: patient and phantom cross-calibration results. 7 Bone Miner Res 1994;9:1503-14.

16 Bjellerup P, Standardization of HPLC measurements of pyridinium crosslinks. Scand $\mathcal{F}$ Clin Lab Invest 1997;227: pyridin
$80-3$.

17 Efthimiou J, Barnes PJ. Effect of inhaled corticosteroids on bones and growth. Eur Respir f 1998;11:1167-77.

18 Pauwels RA, Löfdahl C-G, Laitinen LA, et al. Long-term treatment with inhaled budesonide in persons with mild chronic obstructive pulmonary disease who continue smoking. N Engl f Med 1999;340:1948-53.

19 Pauwels RA, Löfdahl C-G, Postma DS, et al for the Formoterol and Corticosteroids Establishing Therapy (FACET) International Study Group. Effect of inhaled formoterol
and budesonide on exacerbations of asthma. $N$ Engl $\mathcal{F ~ M e d ~}$ 1997;337:1405-11.

20 Wong CA, Walsh LJ, Smith CJP, et al. Inhaled corticosteroid use and bone-mineral density in patients with asthma. Lancet 2000;355:1399-403

21 Toogood JH, Hodsman AB, Fraher LJ, et al. Serum osteocalcin and procollagen as markers for the risk of osteoporotic fracture in corticosteroid-treated asthmatic adults. f Allergy Clin Immunol 1999;104:769-74

22 Malo J-L, Cartier A, Ghezzo H, et al. Skin bruising, adrenal function and markers of bone metabolism in asthmatics function and markers of bone metabolism in asthmatics 1999;13:993-8 